\title{
Study on the Exhibition Design of Gastronomy Theme Based on the Local Culture of Sichuan Province
}

\author{
M.Z. HU \& R.ZHOU* \\ School of Art, Xihua University, Chengdu, China \\ L.F.FEI \\ Department of Digital Art, Chengdu Neusoft University, Chengdu, China \\ *Email:raychou@126.com
}

\begin{abstract}
Gastronomy culture, as one of the forms of the regional intangible culture, is widelyacknowledged in China. With the gastronomy culture in Sichuan as the object, this paper focus on the field investigation in the scenic spots and the food and specialty stores in the featured districts in Chengdu by combining the exhibition design to conduct the comparative studies of the cases and extract the innovation points. The author will thus make an analysis on the situation of the themed exhibition of the food stores in Sichuan as well as the existing problems and propose the key elements of the exhibition design suitable for the theme of gastronomy culture as the suggestions and insights to promote the cultural connotation of the industrial development of Sichuan cuisine.
\end{abstract}

KEYWORD: cultural heritage; local culture; industry of Sichuan cuisine; product of food; exhibition design; international capital of delicacy

Gastronomy culture, as one of the indispensable forms of the local culture and the major areas to generate the intangible culture, is extensively recognized by the public. Among the ascendant humanist tourism patterns, gastronomy culture has been regarded as the important path to experience and perceive the charm of the local culture, even as the cultural symbol of a city and the essential culture resource to promote the urban cultural competitiveness. Let's take Chengdu, one of the three "best tourist cities in China", as an example. After being awarded the title of "city of gastronomy" by UNESCO, gastronomy culture has become the precious cultural resource to market the city and establish the brand image. However, the humanist exhibition around the theme of gastronomy culture has not yet been attached sufficient importance in the following aspects: the elements of the exhibition design in accordance with the properties of the gastronomy culture have not been fully excavated.

\section{PRESENT SITUATION AND PROBLEMS OF THE FOOD EXHIBITION}

Through the field research in the tourist attractions and the local specialty stores in the featured districts in Chengdu, the author will make an analysis on the exhibition design in the stores to arouse the insight of the present situation of the commodity exhibition of the gastronomy culture in Sichuan Province and of the existing problems by selecting the most representative local brands of delicacy such as "Sichuan Specialty", "Siqixiang" and "Zhangfei Beef", etc.

\subsection{Monotonous ways to display}

The current display patterns of the food commodities available in Sichuan can be concluded in two ways, namely, the shelf display and commodity stacking, which is relatively monotonous, particularly for the diversity of the delicacies in Sichuan. The two conventional ways of commodity display cannot manifest the features of the Sichuan cuisine and are lack of originality and novelty. As Jack Trout, Father of Positioning once said, commodity stack, the way of display with distinct Chinese characteristics, deals with the commodity as the bulk without any aesthetics or theme so that it is almost impossible for the consumers to feel impressive (Wang,2012). If the change of the display pattern is only achieved by switching the location of the commodities without any substantial innovation, the consumers would have to spend more time. As a matter of fact, efforts should be made to find the exhibition patterns that accord with the properties of the gastronomy culture in Sichuan based on its uniqueness to satisfy the appeal of the consumers who will be aroused the association and sense judgment of the locality. 


\subsection{Lack of logic in the display}

During the inspection, it was discovered that there is a lack of consideration on the display logic even by the local specialty stores with fame. For example, Brand of "Bafangpin", the brand specialty chain stores of Chengdu are confronted with a lot of problems regarding the commodity display such as unclear division of regions, varied display standard, disorder to the layout, out of order and color mixing, which would consume more time and energy of the customers to find and reach the commodity they need. The color mixing would leave a bad impression on the customers who will lose desire to buy the delicacies. For the exhibition of the delicacies, the consumers' attitude must be given the priority by achieving three principles of "easy to see, easy to select, easy to buy" as the relatively ideal and rational state (Schmitt, 2001). Therefore, display logic must be attached more importance in terms of the display of the food products to make the customers feel relaxed during the purchase.

\subsection{Absence of the cultural features}

Local specialties require special memory points of people, for what they deliver are different local cultures due to their necessary relevance to the local culture. Thus the association aroused by the local culture can be made full use of in the display of the food commodity to deepen the impression of the consumers on the local delicacies. The local specialty stores can position the exhibition styles according to their own features by combining the features of the specialties to create the purchase environment. For example, "Siqixiang" is a famous franchised store of local specialties of Liangshang regions focusing on the local specialties with Yi Nationality characteristics such as beef and black tartary buckwheat. If the design elements of $\mathrm{Yi}$ Nationality such as the colors, folk ornamentation and characters could be adopted, "Siqixiang" would have its own style and cultural elements with local features to elevate the cultural experience of the delicacies.

\section{COVERAGE OF THE TOURIST COMMODITIES IN THE GASTRONOMY CULTURE OF SICHUAN PROVINCE}

\subsection{Forms and contents of the commodities}

"Sichuan Food", as a common category, is different in many ways with the commodity of gastronomy culture. For example, the instant snacks such as Dandan Noodle and Shangxin Bean Jelly can be classified into the dishes which do not belong to the category of the tourist commodity of gastronomy culture which is smaller than "Sichuan Food" in the general sense. Besides the thematic factor of culture, it should be in line with the definition of the universal tourist commodity of culture. For Sichuan cuisine may be called as the first cuisine of China with extensive public basis and historical accumulation, the patterns and variety of the tourist commodity of gastronomy culture in Sichuan are exceptional rich. In terms of the common ways of commodity display, there are generally five categories, namely, tea and liquor, flavor food, snacks and appetizers, local specialties of agroforestry as well as cooking seasonings. For more details of the division, please refer to Figure 1, to watch clearly about the coverage of the tourist commodities of the gastronomy culture in Sichuan.

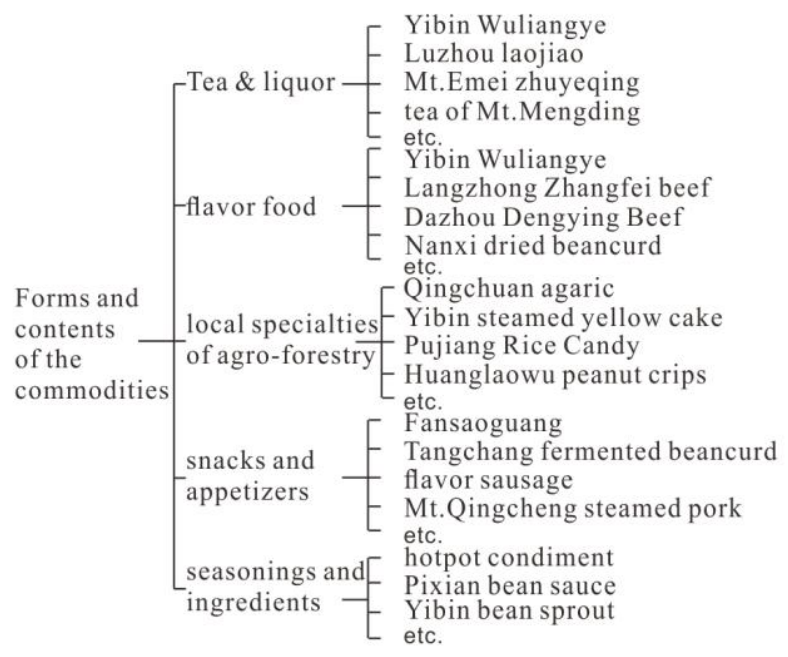

Figure 1. Tree diagram of the tourist commodities in the gastronomy culture in Sichuan Province

\subsection{Category of the contents in the exhibition}

The abundance of variety of the tourist commodities of the gastronomy culture in Sichuan also means that the ways to exhibit the commodities are not limited to placing or stacking. From the angle of exhibition design, the differences in the commodity forms must be put into consideration to adopt suitable designs. Therefore, in the first place, it must regard the commodities as the contents in display by analyzing their packaging forms. Figure 2 is the tree diagram of the types of the contents concluded according to the materials and packaging of the commodities popular in the market.

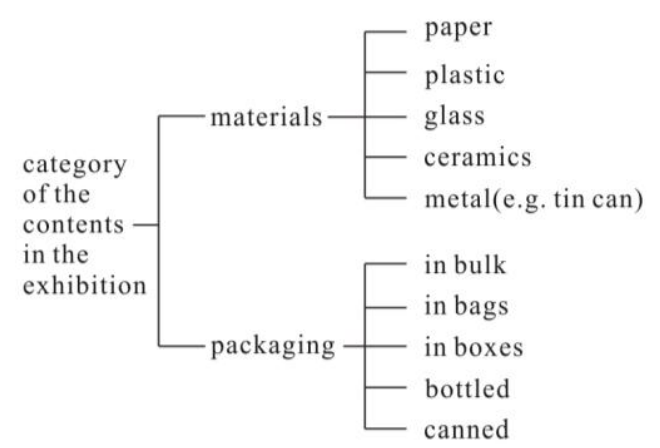

Figure 2. Category of the contents in the exhibition 


\subsection{Characteristics of the food commodities in Tourism}

If the so called "food" in the daily life is shifted to be defined as tourist commodities with local delicacy as the theme, it should have the common features of the tourist commodities in the general sense and at the same time accord with the property of the local gastronomy culture. The features exclusively to the tourist commodities of delicacy are as follows:

1) Portability. The packaging should be easy, portable and breakage-proof. The tourists may consider if the local specialty is easy to carry. Whether the specialty will increase the burden during the trip is one of the major factors to decide the purchase of the tourist commodities of delicacy.

2) Memorial. The packaging and flavor of the local specialty should have Sichuan characteristics to feel and arouse the memory of the local delicacy with the delicious food. Most of the tourists purchase the local specialties as keepsake or gifts for their relatives or friends as well as the imagination of the local culture.

3) Instant eat. Most of the local food is instant food requiring no processing or cooking. It can save time and energy so that the tourists can enjoy the food anytime during the journey.

4) Simplicity. The cooking process is simple and time-sparing, particularly for the non-local consumers and tourists who are not required to have complicated cooking techniques and knowledge. For example, the hotpot condiment and Luzhou steamed yellow cake which require simple processing and cost little time to prepare.

5) Regionalism. The local delicacies generally have strong local characteristics, from which the tourists can perceive the cooking culture, natural environment and social customs of Sichuan. Since those local characteristics are exclusive to the region, they can help obviously differentiate the local specialties from the food commodities in the other provinces.

\section{THE CONSTRUCTION ELEMENTS OF EXHIBITION FOR CULTURE EXPERIENCE}

\subsection{Creating the scene scenario}

The creation of setting scenario should focus on easiness and joy. Besides the tourists, the local consumers are also the consumer groups of local cuisine. A good setting scenario can always increase the desire to purchase of the consumers, who are sensitive receptors with rich thoughts and feels. Therefore, our senses be should combined with vision to create the scenario synthetically. But the sensory experience is no single, the hearing, tasting, smelling and touch sensations can inspire the abstract or figurative association of the consumers (Yu \& Chen, 2007). Therefore, the food exhibition is not only the matter of showing the food goods, a related ornament or prop can be put beside the local food. The touch of the ornaments and smelling of the food materials can deepen the impression of the consumers on the regional features of the food and vividly make them experience the distinctive culture of the food. Creating the production, manufacturing links and enjoying the atmosphere, feeling the pleasure of sharing local food, experiencing the spirit of the food culture and feeling the languages behind the local cuisine can help the consumers to feel the internal background of food culture while selecting and purchasing the food. For the food exhibition, it cannot be limited to the exhibition way of food exhibition. It can be restored the scene by learning from the usual ones of fashion shows to create the atmosphere.

\subsection{Straightening the color sequence}

The color sequence is an important component factor of exhibitions and a good color sequence can give people a pleasant feeling of clean, tidy and comfort; otherwise, it will make people restless with disorder and dirtiness. The food packages have their own colors, which need to be reasonably and orderly combined and arranged in the exhibition to increase the appetite of the consumers so as to promote their purchasing behavior. Taking the Food Zone of Ole's Specialty Supermarket in Chengdu MIXC as an example, this supermarket pays much attention on the color sequence of the food. To find the potential design logic of the traditional shelf display methods of the goods, the color tone is refined and analyzed. The specific way is shown as Figure 3: (a) the exhibition of the food products-(b) dynamic effect fuzzification and pixilation generalization as the check-out lane sight-(c) extracting the tone of the overall color lump, and restoring it on the display shelf, From which we know that the packaging color of the food mainly adopts the active and warm tone, and uses the bright, shining and clear colors. The consumers will link the bright and clean purchasing environment and the novel and superior products together (Yuan, 2010), so the fresh colors will make people think that the food is clean and fresh. By matching of the similar color schemes, the whole display shelf will have a sense of order, which will attract the eyeballs of the consumers. Sichuan Culture \& Food Thematic Exhibition should straighten the color sequence of the food, use this color sequence setting way to create a tidy and comfortable purchasing environment.
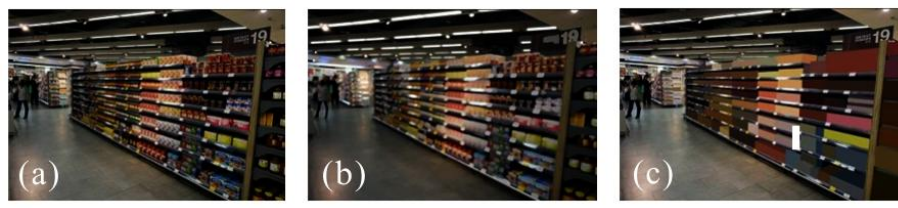


\subsection{The association of the culture symbol}

With the development of the local cuisine, the competition between the foods has become more and more fierce. So the cultural features should be stressed on highlighting the food specialty. In the food exhibition, the originality of culture symbol should be paid more attention. Generally speaking, when entering the shop, the whole process of purchasing goods generally includes "perceptioninterest-attention-association-desire-comparisiondecision-purchasing" (Wang, 2005). To impress the consumers instantly when they are facing numerous foods with local cultural features, the food itsself must has its own unique feature. Sichuan Province has rich local cultural resources, which have the bright local features and hence can be transformed into cultural symbols. For example, the facial masks in Sichuan opera, Sunbird, the National Treasure Panda and pepper can be the representative cultural symbols of Sichuan, which can be used properly on the ornaments and exhibitions. When the consumers see those symbols, they would think of Sichuan and feel the local customs and ethnic culture. For example, on the package of Zhangfei Beef, the facial masks of Zhangfei in Sichuan Opera are used as the design elements. Similarly, the corresponding symbols can also be used in the exhibition design. Therefore, taking full advantage of the association caused by the cultural symbols can increase the sense of details of the store and impress the consumers in their purchasing process; meanwhile, it can improve the uniqueness of the food products and improve competitiveness by using the culture symbols.

\subsection{The diversification of display methods.}

In the current market, most of the food stores adopt the channel exhibition stands, that is, the exhibition stands form the road passage for leading the consumers to select and purchase. But this single display method cannot completely show the topicality and specialty of the food. Besides, the supermarkets also use the POP display method, which pile up the canning and box and other different packages to form the layering that is similar to the toy bricks. Meanwhile, matching the foods according to the colors to improve the original disorder display method, which can increase the desire of purchase in some degree. Due to the richness of the content and the regional features of food products, Sichuan cuisine should explore the diversified display methods according to their own characteristics. For example, bamboo weaving package can use suspension type display, which can attract the attention of the consumers even if they are

\section{THINKING ON LOCALIZATION AND INTERNATIONALIZATION}

Chengdu was entitled as "City of Gastronomy" by UNESCO in February, 2010, becoming the first city in Asia to win this honor. According to the criteria on "City of Gastronomy", it pays much attention to the cooking technique of local cuisine and the production of local traditional products. Therefore, to promote the image tag of "City of Gastronomy", Chengdu must strengthen the protection and inheritance of traditional cuisine, attach importance to the propagation of cuisine by exhibitions and promote cultural communication. Chengdu should reserve local traditional gastronomy culture while promoting the city internationalization, focus on strengthening the cultural connotation of Sichuan local gastronomy culture and think about how to combine the local and the international by tourism 
industry. In 2014, China National Tourism Administration raised the concept "must-buy" in the tourism commodities exposition, making the cuisine commodities become the most important category among the recommended commodities.

Chengdu, as an international city of gastronomy, its local cuisine has also become an indispensable part of local culture. Some gastronomy culture has also become national intangible cultural heritage and has been raised in the policy of "application for the list of world heritage". In this aspect, South Korea has been in the lead. Therefore, the exhibition design which agrees with the subject of gastronomy culture should play its role in promoting communication, propaganda and elevating the industrial cultural value and advancing the internationalization of local gastronomy culture. During propaganda and operation of the international city title "City of Gastronomy" contains and develops gastronomy culture, pays more attention to the integration of local culture and inherit and protect various kinds of cultural resources, and help Chengdu to focus on promoting city's culture soft power, and create the innovation capacity of the city (Zhou, 2013).

\section{CONCLUSION}

Gastronomy culture is an important part of Sichuan culture, and it has begun to explore the progress of international influence since Chengdu won the title of "City of Gastronomy". During the transmission of gastronomy culture, each specialty store is playing the role of promotion and has considerably deep and extensive influence on tourists visiting Chengdu. Homologous attention should be paid to Sichuan cuisine tourism commodities to make it agree with the design of the rule and motivation of tourism consumption behavior as well as raise the cultural connotation value by design innovation to present the charm of Sichuan local culture. Promoting the exhibition design of the cuisine subject should be one of the measures to further construct the city image of international "City of Gastronomy", aiming at the two core targets of inheritance and development, constructing the industrial height of gastronomy culture to create favorable conditions for promoting the culture soft power of the city and advance the international influence of Sichuan local culture by the window of gastronomy culture.

\section{ACKNOWLEDGMENT}

Fund Program: 2012 Annual Planning Project of "Development and Research Center of Sichuan Cuisine", Key Research Base of Humanities \& Social Sciences, Education Office of Sichuan Province (Project Number: CC12S10).

\section{REFERENCES}

[1] Wang, Y.X. 2012. Chinese-style store display. Journal of China Marketing (Channel edition) 11:62-63.

[2] Schmitt, B. 2001. Marketing aesthetics. Shanghai: Shanghai Jiaotong University Press.

[3] Yu, X.F. \& Chen, S.C. 2007. Exhibition design for life-style experience based on the inspiration of constitutive characteristics of CATHAYA brand's display. Journal of Silk 12:18-21.

[4] Yuan, X.B. 2010. Analysis on the market layout and display design of Supermarkets. Times Finance 06:192-194.

[5] Wang. W.Z. 2005. Psychological art of supermarket display. Journal of Haebin University of Commerce (Social Science Edition) 85 (6):88-90.

[6] He, Z. 2014. Sense feast of interactive technology \& Touch the infinite imagination of cuisine. Newspaper of Chengdu Economic Daily. 2014-03-12 (30).

[7] Zhou, R. 2013. Cultural creative design for the image of Chengdu as an UNESCO city of gastronomy. Journal of Packaging Engineering 3(10):83-86. 